\title{
Leveling measurements of antifouling coatings using an optical profilometer: Effects of additives and solvent concentration and type
}

Wang, Xueting; Erik Weinell, Claus; Tobar, Vicenç; Olsen, Stefan Møller; Kiil, Søren

Published in:

Progress in Organic Coatings

Link to article, DOI:

10.1016/j.porgcoat.2019.03.037

Publication date:

2019

Document Version

Peer reviewed version

Link back to DTU Orbit

Citation (APA):

Wang, X., Erik Weinell, C., Tobar, V., Olsen, S. M., \& Kiil, S. (2019). Leveling measurements of antifouling coatings using an optical profilometer: Effects of additives and solvent concentration and type. Progress in Organic Coatings, 132, 159-168. https://doi.org/10.1016/j.porgcoat.2019.03.037

\section{General rights}

Copyright and moral rights for the publications made accessible in the public portal are retained by the authors and/or other copyright owners and it is a condition of accessing publications that users recognise and abide by the legal requirements associated with these rights.

- Users may download and print one copy of any publication from the public portal for the purpose of private study or research.

- You may not further distribute the material or use it for any profit-making activity or commercial gain

- You may freely distribute the URL identifying the publication in the public portal 


\title{
Leveling measurements of antifouling coatings using an optical profilometer: effects of additives and solvent concentration and type
}

\author{
Xueting Wang ${ }^{\mathrm{a}, 1}$, Claus Erik Weinell ${ }^{\mathrm{a}, 2}$, Vicenç Tobar ${ }^{\mathrm{b}}$, Stefan Møller Olsenc ${ }^{\mathrm{c}}$, Søren Kiil ${ }^{\mathrm{a}, *}$
}

${ }^{a}$ CoaST, Department of Chemical and Biochemical Engineering, Technical University of Denmark (DTU), Building 229, 2800 Kgs. Lyngby, Denmark

${ }^{1}$ E-mail: xewa@kt.dtu.dk

${ }^{2}$ E-mail: cwei@kt.dtu.dk

${ }^{\text {b} D e p a r t m e n t ~ o f ~ F o u l i n g ~ C o n t r o l, ~ P i n t u r a s ~ H e m p e l ~ S . A . U ., ~ C a r r e t e r a ~ S e n t m e n a t ~ 108, ~} 08213$ Polinyà, Barcelona, Spain

E-mail:vtp@hempel.com

Telephone: +34937130000

cDepartment of Fouling Release Systems, Hempel A/S, Lundtoftegårdsvej 91, 2800 Kgs. Lyngby, Denmark

E-mail: stmo@hempel.com

Telephone: +4545933800

*Corresponding author, e-mail: sk@kt.dtu.dk, telephone: +45 45252827

Declarations of interest: none 


\section{Abstract}

Ship hulls require smooth antifouling coating surfaces to decrease frictional drag and avoid sites of weakness for biofouling. Consequently, the leveling properties of antifouling coatings should be understood and optimized. In the present work, a novel approach to quantitatively measure leveling properties of coating films was developed. Using this approach, dynamic surface textures during leveling of selected model antifouling formulations were measured using a combination of a threedimensional (3D) profilometer and a retrofitted automatic film application system. It was found that the leveling process is strongly coupled to the solvent evaporation rate and the associated development in coating viscosity. For low viscous coatings, three leveling stages were observed. High viscous coatings, on the other hand, only went through one leveling stage.

Experimental data showed that an underlying tie-coat (relative to a flat acrylic panel) had negative effects on the smoothness of the top coat. In addition, using an anti-sagging agent enabled control of sagging, but resulted in negative effects on leveling. Nevertheless, it was still possible to obtain good leveling performance with anti-sagging agent in a formulation.

The effects of minor amounts of three types of additives and two types of solvents on leveling of the model formulations (drawdown application) were found to be less significant than those seen during (and after) spraying application. It is therefore important to take into account the application method when studying leveling phenomena.

\section{Keywords}

Leveling measurement; Antifouling coating; Surface texture; Solvent; Additive; Sagging

\section{Abbreviations}

AF: antifouling; 3D: three-dimensional; DHR: Discovery Hybrid Rheometer; FCC: fouling control coating; FR: fouling release; ISO: International Organization for Standardization; PDMS: poly(dimethyl)siloxane; RPM: revolutions per minute 


\section{Introduction}

On ship hulls, various layers of protective coatings are applied to fulfil different requirements. The outermost layer is normally a fouling control coating (FCC) of which the primary role is to limit biofouling and the associated drag resistance $[1,2]$. However, following application, the coating surface is not entirely smooth, having both roughness and waviness. An irregular surface not only affects the esthetics but also constitutes sites of weakness, i.e., potential starting points for corrosion, cracking, blistering and biofouling [3,4,5]. In addition, a non-smooth FCC surface will increase the frictional resistance itself [2]. Therefore, it is desirable to obtain smooth FCC surfaces, though the major benefits will be seen only when the ship is still free of biofouling.

Both waviness ('long' wavelength surface patterns) and roughness ('short' wavelength surface patterns) can have an influence on the drag of a ship hull surface, but in this work we have assumed that the waviness is the dominating factor. The work of Townsin et al. [6] supports this assumption; they found that the drag of a roughened propeller in service was strongly dependent on the wavelengths above 0.8 $\mathrm{mm}$ (an increase in the drag of over $50 \%$ was seen when the cut-off wavelength was increased from 0.8 to $2.5 \mathrm{~mm}$ and a change of 100 percent in drag resulted from reducing the cut-off wavelength to 0.25 $\mathrm{mm})$. It should be noted, however, that the choice of cut-off wavelength often depends on the specific surface under exploration, and that no universal agreement on cut-off length seems to have been established though recommendations (i.e. $0.08,0.25,0.8,2.5$, or $8 \mathrm{~mm}$ ) can be found in ISO standards $[7,8]$. To ease comparison, it is recommended to always provide the cut-off lengths applied in a given investigation. Anyway, the present work is focused on the rate and degree of coating leveling and does not cover drag force measurements. 
During spraying application, the shear rate of coatings may go up to $10^{4}-10^{6} \mathrm{~s}^{-1}$. Immediately after application, coatings are subjected to a low shear rate range of $10^{-1}$ to $10^{-2} \mathrm{~s}^{-1}$, where leveling occurs. If the coating is applied to a vertical (or slanted) surface, sagging, due to gravitational effects, can also be important. The shear rate range where sagging is taking place (about 1 to $10^{-2} \mathrm{~s}^{-1}$ ) can overlap with that of leveling [9]. As a result, the leveling (desired) and sagging (undesired) phenomena are coupled.

\subsection{Leveling of coatings}

For most coatings, a smooth surface can be achieved by proper leveling and the first studies of this can be dated back to the 1920s. However, advances in understanding the mechanisms and the influencing factors have been slow [10]. Waring [11] was probably the first, in 1931, to conduct an analytical study of leveling of a pigment-vehicle mixture. Later, in 1961, leveling phenomena (brush mark studies) were described by Smith, Orchard, and Rhind-Tutt. They stated that leveling is mainly driven by surface tension and retarded by viscous drag [12]. In 1962, Orchard [13] studied leveling theoretically; the so-called Orchard equation is representative of the leveling process, where the amplitude of a sinusoidally rippled liquid surface decreases exponentially with time. The rate of leveling was found to be a function of the average film thickness, the surface tension, dynamic viscosity and the ripple wavelength. Orchard found that the gravitational effect can be neglected when the wavelength is less than about $3 \mathrm{~mm}$. Due to various simplifying assumptions, the equation is only applicable to nonvolatile liquids and Newtonian flow, far from non-Newtonian coatings rheology. Experimental work of Overdiep [14] showed that the Orchard equation fails to give a qualitative description of leveling of solvent-based alkyd coatings. Overdiep found that the so-called Marangoni-effect (a term used to describe a surface-tension-gradient [15]) resulting in a "reversal process" was another driving force for

leveling. The "reversal process" means that the initial peaks would become valleys and the initial 
valleys would become peaks. The mechanism is, as explained by Wilson [16], that the solvent concentration near peaks is higher than that near valleys during solvent evaporation, which results in a lower surface tension near the peaks. This gradient drives flow from peaks to valleys, which enhances the leveling process. Due to the imbalance in solvent concentration, this process will continue and the reversal phenomenon is the result. Based on the Overdiep model, Wilson continued with development work on models for coating films [16-18]. However, these investigations were highly ideal because they neglected the dependence of coating viscosity on shear rate, the effects of thixotropy, and the presence of solvent evaporation [10]. Later, 1995-2011, leveling studies were focused in different directions: numerical simulation of the Marangoni-effect on leveling of a two component fluid [19], the thix otropic effect on leveling [20,21], and leveling of thermoset waterborne coatings [22,23].

Approaches for studying and quantifying leveling have been pursued [14,24,25]. However, most of the previous methods were specifically designed to certain type of coating systems or could not be applied directly to coating films containing solvents. Recently, novel approaches for leveling studies were reported for powder and automotive coating systems, which are both different compared to FCCs. Bosma et al. [26] developed a method for estimation of leveling behavior of powder coatings in a quantitative manner and the evolution of surface texture in automotive coatings was studied in details by Peters et al. [27]. A very recent work presented by Seeler et al. [28] investigated coating film leveling through simulations and experiments; however, most samples presented were simplified systems: Newtonian model liquids with and without solvent evaporation.

In the present work, a new approach for measuring leveling of coatings was developed. It involves a combination of an automatic spiral-drawdown application and a 3D measurement system based on a profilometer. Using this macroscopic approach, a well-defined sinusoidal surface pattern could be 
formed on the coating surface. The dynamic surface texture information was collected nondestructively in short intervals during leveling and solvent evaporation.

\subsection{Strategy of investigation}

Two main types of FCCs, with different antifouling mechanisms, are commercially available. One is the fouling release (FR) coatings, which present a smooth surface with low surface energy and high elasticity that makes it difficult for marine species to adhere during sailing. The other is the traditional biocide-based antifouling (AF) coatings, which are normally highly pigmented coatings containing biocides that are released into seawater to limit biofouling. For AF coatings, the solids content (about $80 \mathrm{wt} \%$ or $58 \mathrm{vol} \%$ ) is very high and the final coating surfaces are less uniform than the ones of FR coatings. Consequently, to investigate significant effects, the target of this leveling study was model AF formulations based on commercial AF coatings. Unlike FR coatings, AF coatings cure by physical drying only.

The aim of the work has been to study the effects of coating ingredients on leveling of AF coatings and investigate the underlying leveling mechanisms. The ingredients considered were a silicone additive (silicone oil), a silicone surfactant (leveling additive), a wetting and dispersing agent, and a solvent. The motivation for choosing these ingredients are based on previously published investigations and advice given to us by experts in the coating industry. Schwartz and co-workers [29] found that the presence of surfactant slowed down the leveling rate of Newtonian liquids due to the resulting Marangoni-effect. For the solvent case, less volatile solvents should slow down the evaporation rate and consequently prolong the drying time, which may leave longer time for leveling before the coating loses its flow ability due to viscosity build-up. For most AF coatings, wetting and dispersing agents are used to assist rosin in the wetting and covering of pigment surfaces, thereby expelling air and water, 
and enhance pigment dispersion. Accordingly, these additives may have an influence on leveling and many types are commercially available for coatings. In practice, leveling and sagging are conflicting; good conditions for leveling may lead to sagging problems. As a result, optimal conditions are pursued to get the best leveling without causing sagging. Thus, the effects of anti-sagging agents are included in the present investigation.

\section{Equipment and methodology}

\subsection{Equipment}

A wide-area 3D measurement system (profilometer) with a VR-3100 sensor head from KEYENCE was used in this work to obtain dynamic surface texture information through scanning of solvent-containing coating surfaces. The coating film application was performed using a system as shown in Figure $\mathbf{1}$ (left) based on retrofitting a commercial film applicator (Coatmaster from Erichsen). The aluminum part above the glass provided horizontal movement with adjustable speed and moving direction. A spiral rod applicator is placed in front of the moving part as shown in Figure $\mathbf{1}$.

To start the measurements immediately after application, without handling the sample, film application was performed directly on top of the specimen stage of the VR-3100 head (see Figure $\mathbf{1}$ right) which is located on the right side of the film application system. Notice that it is important to obtain instantaneous surface information right after application because leveling starts immediately. All the coating samples were applied on panels. A template was placed on top of the stage to fix the position of the panels so that the same position of each panel was measured every time. 

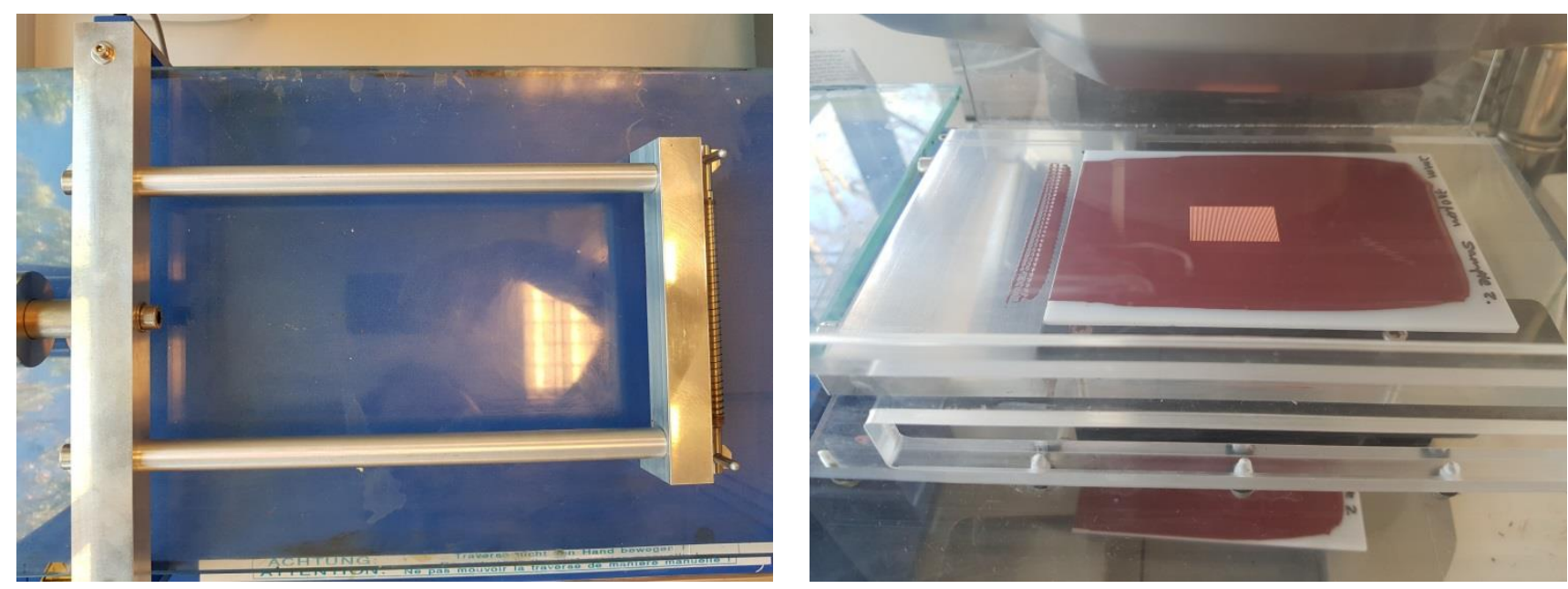

Figure 1. The retrofitted automatic film application system (seen from the top) (left) and the specimen stage of the VR-3100 head (right).

\subsection{Roughness and waviness profile}

The profilometer provides surface information with various surface texture parameters. The texture of a ship hull surface is a complex function of superposed undulations and cannot be described by a single parameter [30]. In fact, it was reported that more than 59 surface texture parameters can be used to describe a surface geometry [31]. However, it is not realistic to use all of them for scientific comparisons and research. Generally speaking, a ship hull surface profile consists of two major components: roughness and waviness, which have different scales of wavelength (see Figure 2). During measurements using the profilometer, the surface profile can be filtered by introducing appropriate cutoff wavelengths. Firstly, a primary profile can be obtained by applying a low-pass cut-off wavelength $\lambda_{\mathrm{s}}$ to remove the wavelength components shorter than $\lambda_{\mathrm{s}}$. The removed components are regarded as not relevant to a targeted roughness profile. Following, if a high-pass filtering of the profile with a cut-off wavelength $\lambda_{c}$ is used, then the characteristics with longer wavelength (waviness) will be filtered out and basically the roughness profile is obtained. If the profile is low-pass filtered with a cut-off 
wavelength $\lambda_{c}$ and high-pass filtered with a cut-off wavelength $\lambda_{\mathrm{f}}$, the wavelength characteristics shorter than $\lambda_{\mathrm{c}}$ and longer than $\lambda_{\mathrm{f}}$ are removed and the waviness profile is obtained as illustrated in Figure 2 [32]. On ship hull surfaces, the wavelengths of the surface profiles are not uniform and have a distribution typically from 0.1 to $30 \mathrm{~mm}$. Surface irregularities with wavelengths between 1 and $10 \mathrm{~mm}$ are known as orange peel [28].

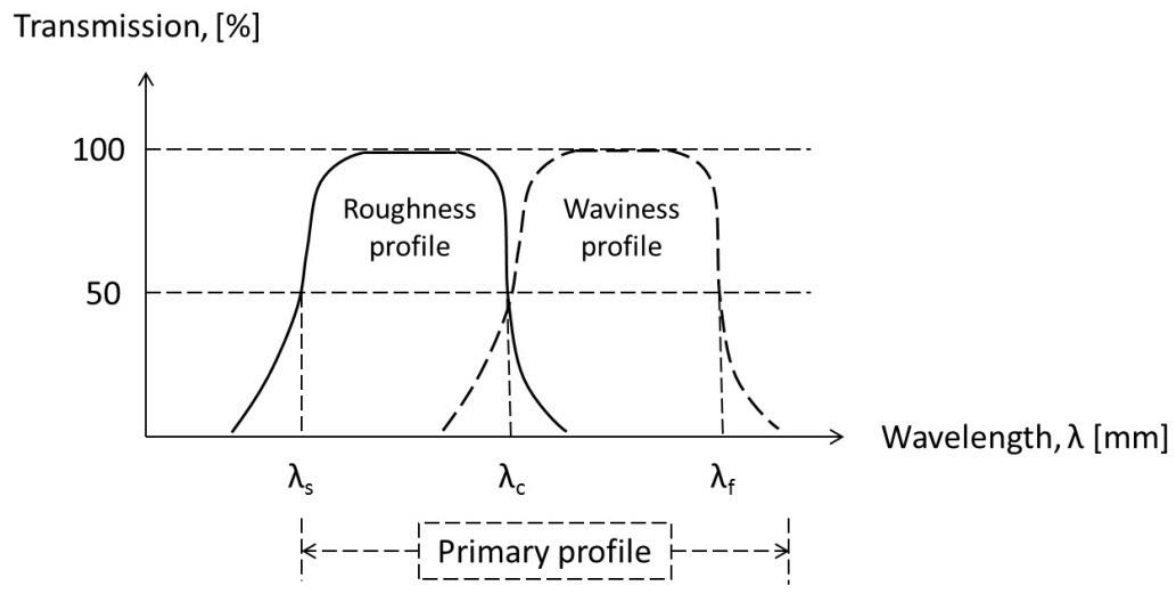

Figure 2. Differentiation of roughness and waviness characteristics by using filtering cut-off wavelengths based on International Standardization Organization (ISO) standards [32].

\subsection{Materials}

Based on commercial AF coatings, various model formulations were formulated. The raw materials were supplied by Hempel A/S. Coatings were produced using high-speed dispersion and basic mixing of ingredients was done using a shaker. During coating sample preparation, the fineness of grind was targeted to a maximum of $40 \mu \mathrm{m}$. Subsequently, the viscosities of model formulations were measured at $25^{\circ} \mathrm{C}$ and a shear rate of $117.4 \mathrm{~s}^{-1}$ using a Discovery Hybrid Rheometer (DHR-2) from TA Instruments with parallel plate geometry. The diameter of the upper plate was $40 \mathrm{~mm}$ and the gap between the two parallel plates was $500 \mu \mathrm{m}$. The shear rate was chosen for comparison with the 
viscosity values measured using a KU-1 Viscometer from Brookfield at 200 revolutions per minute (RPM). Normally, the viscosity of commercial AF coatings is about $0.95-2.2 \mathrm{~Pa} \cdot \mathrm{s}$ at $117.4 \mathrm{~s}^{-1}$.

Due to the fact that the viscosity of model formulation 1 (M1) turned out to be extremely high (>8 Pa.s) after preparation, model formulation 2 (M2) was formulated after minor modifications of M1 to reach a lower viscosity of about $2.2 \mathrm{~Pa} \cdot \mathrm{s}$. Furthermore, to determine the effects of viscosity on leveling, the M1 coating was diluted with xylene (the main solvent) to reach a relative moderate viscosity of about 4.3 $\mathrm{Pa} \cdot \mathrm{s}$ (not shown in Table Fejl! Henvisningskilde ikke fundet., see Table Fejl! Henvisningskilde ikke fundet. "M1-diluted"). To control sagging and investigate the influence of anti-sagging agent, another model formulation M3 was formulated by adding an anti-sagging agent. The compositions of M1, M2 and M3 are shown in Table Fejl! Henvisningskilde ikke fundet..

Table 1. Compositions of model formulations M1, M2, and M3 (in weight percentage).

\begin{tabular}{|l|l|l|}
\hline M1 & M2 & M3 \\
\hline $\begin{array}{l}\text { Xylene/Dimethylbenzene } \\
(20 \%)\end{array}$ & $\begin{array}{l}\text { Xylene/Dimethylbenzene } \\
(22.5 \%)\end{array}$ & $\begin{array}{l}\text { Xylene/Dimethylbenzene } \\
(21 \%)\end{array}$ \\
\hline $\begin{array}{l}\text { Methyl isobutyl ketone } \\
\text { solvent (4\%) }\end{array}$ & $\begin{array}{l}\text { Methyl isobutyl ketone } \\
\text { solvent }(4 \%)\end{array}$ & $\begin{array}{l}\text { Methyl isobutyl ketone } \\
\text { solvent }(4 \%)\end{array}$ \\
\hline Zinc oxide $(10 \%)$ & Zinc oxide $(10 \%)$ & Zinc oxide $(10 \%)$ \\
\hline Bentonite $(2 \%)$ & Bentonite $(1.5 \%)$ & Bentonite $(2 \%)$ \\
\hline Talc $(12 \%)$ & Talc $(11 \%)$ & Talc $(11 \%)$ \\
\hline Cuprous oxide $(24 \%)$ & Cuprous oxide $(24 \%)$ & Cuprous oxide $(24 \%)$ \\
\hline Gum rosin $(18 \%)$ & Gum rosin $(18 \%)$ & Gum rosin $(18 \%)$ \\
\hline Acrylic binder $(10 \%)$ & Acrylic binder $(9 \%)$ & Acrylic binder $(8 \%)$ \\
\hline & & Polyethylene wax $(2 \%)$ \\
\hline
\end{tabular}

To investigate the effects of different solvents and additives on leveling of model formulations, coating samples were prepared as listed in Table Fejl! Henvisningskilde ikke fundet.. Different amounts of xylene $(5,7,10 \mathrm{wt} \%)$ were replaced by naphtha (a less volatile solvent), here termed $\mathrm{A}$, for three model 
formulations. It was suggested to replace maximum $10 \mathrm{wt} \%$ of xylene with solvent A by experts from coating industry. In addition, $2 \%$ of additives were added to M2 and M3 respectively. Additives B and C were acquired from BYK Additives \& Instruments. Adding 2 wt $\%$ of an additive changes the concentration of the other ingredients in the formulation by maximum $0.5 \mathrm{wt} \%$, which was considered sufficiently low to neglect the scaling of the other compound concentrations accordingly.

Table 2. Coating samples with preparation method and notation. A=naphtha solvent (less volatile than xylene), $B=$ solution of a polyether-modified polymethylalkylsiloxane (silicone surfactant/leveling additive), $\mathrm{C}=$ salt of a polymer with phosphoric acidic groups (wetting and dispersing agent), and $\mathrm{D}=$ poly(dimethyl)siloxane (additive normally used in FR coatings) [33]

\begin{tabular}{|l|l|}
\hline Sample notation & Preparation \\
\hline M1 & Follow formulation M1 \\
\hline M2 & Follow formulation M2 \\
\hline M3 & Follow formulation M3 \\
\hline M1-diluted & Diluting M1 with xylene \\
\hline M1-A-5\% & Replacing 5\% of xylene with A for M1 \\
\hline M1-A-7\% & Replacing 7\% of xylene with A for M1 \\
\hline M1-A-10\% & Replacing 10\% of xylene with A for M1 \\
\hline M2-A-10\% & Replacing 10\% of xylene with A for M2 \\
\hline M3-A-10\% & Replacing 10\% of xylene with A for M3 \\
\hline M2-B-2\% & Adding 2\% of B to M2 \\
\hline M2-C-2\% & Adding 2\% of C to M2 \\
\hline M2-D-2\% & Adding 2\% of D to M2 \\
\hline M3-C-2\% & Adding 2\% of C to M3 \\
\hline
\end{tabular}

\subsection{Methodology}

The substrates used in the investigations were acrylic panels with a thickness of $3 \mathrm{~mm}$. Using the profilometer in the absence of a cut-off length, the average surface roughness of the substrate panel was 
measured to about $16 \mu \mathrm{m}$. Due to the initial coating thickness (about $300 \mu \mathrm{m}$ ), the substrate surface texture does not influence the waviness measurement of the coatings.

To conduct the film application, two types of applicators were designed and manufactured as shown in Figure 3. The flat applicator (left) resulted in a flat geometry on top of the coating film and the spiral applicator (right) provided a well-defined sinusoidal surface geometry similar to brush marks and surface patterns after spraying. Both applicators gave around $300 \mu \mathrm{m}$ of wet film thickness. The wavelength of the sinusoidal geometry was defined by the gap between two spiral coils, which is approximately $3.7 \mathrm{~mm}$. The two applicators were made of stainless steel-316.
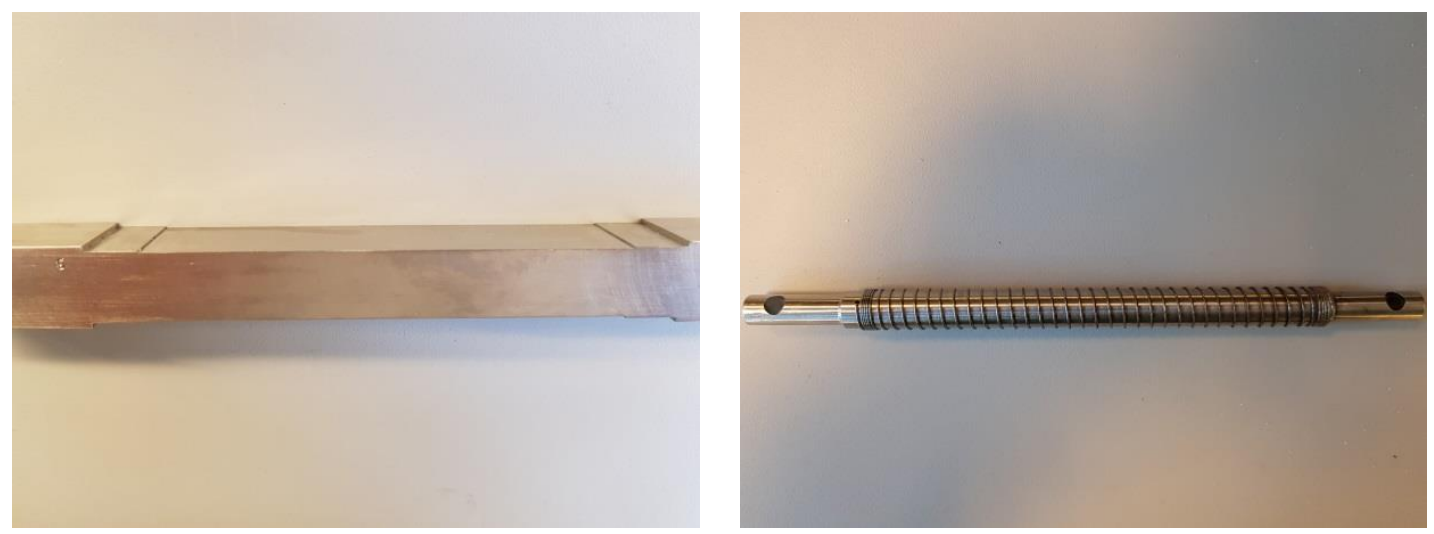

Figure 3. The two types of applicators used in the investigations: flat applicator (left) and spiral applicator (right).

It was found that the position where coating samples were placed on the panels and the sample volume had an influence on the evenness of the coating film thickness. To obtain an even coating film, the sample volume was set to $9 \mathrm{ml}$ (added by pipette). Moreover, the sample was placed at the same position on the panel and with the same loading pattern every time (using a mold as shown in Figure 4). 


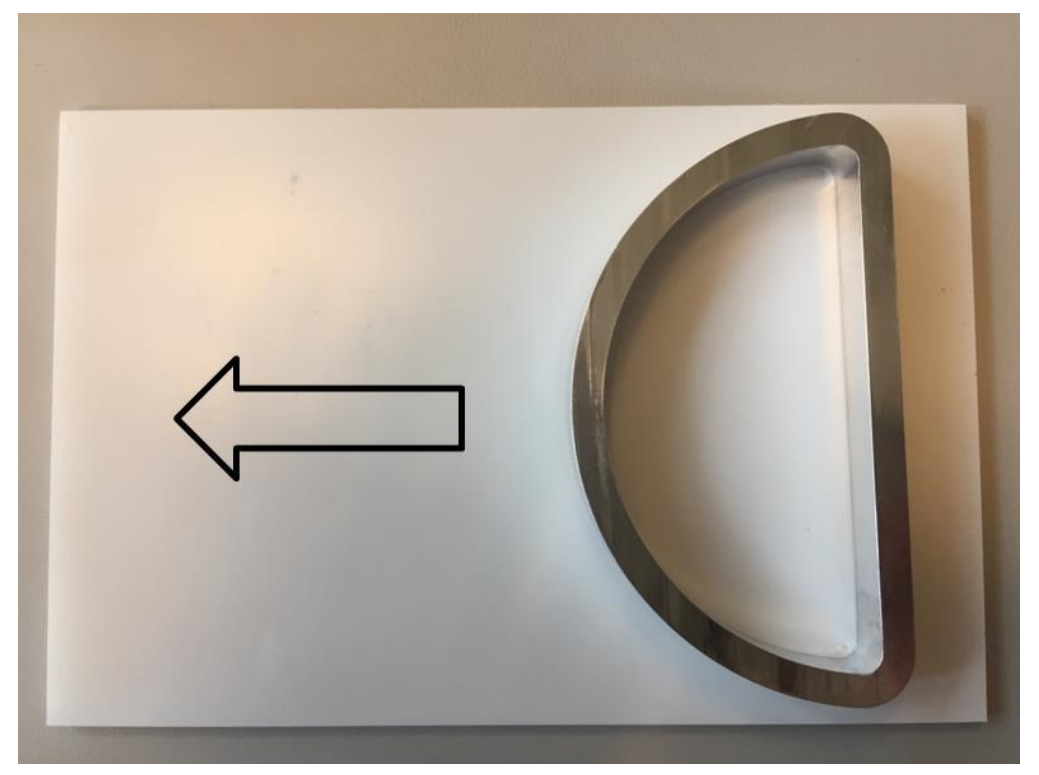

Figure 4. Mold used for loading liquid coating samples. The arrow indicates the direction of coating film application.

In the evaluation of surface leveling properties, various surface texture parameters were considered: the average height for roughness profile ( $\mathrm{Ra}$ ) and waviness profile (Wa) of multiple defined lines in the scanned sampling area, the average maximum peak to valley distance for roughness profile (Rz) and waviness profile $(\mathrm{Wz})$ of multiple lines in the scanned sampling area, and the average height at each measurement point in the scanned sampling area $(\mathrm{Sa})$. The parameter calculating methodologies employed comply with ISO standards [34,35].

When applying different cut-off wavelengths, $\lambda_{c}(0.25 \mathrm{~mm}, 0.8 \mathrm{~mm}$, and $2.5 \mathrm{~mm})$, to the same surface measurement, the values of Ra were affected, while the effects on Wa were practically insignificant as shown in Figure 5. Since $\lambda_{c}$ defined the upper limit for the roughness $(\mathrm{Ra})$, an increase of $\lambda_{c}$ from 0.25 $\mathrm{mm}$ to $2.5 \mathrm{~mm}$ included higher roughness characteristics. However, for waviness (Wa), the increase of $\lambda_{c}$ as the lower limit, excluded lower waviness characteristics from the waviness profiles. Consequently, 
$2.5 \mathrm{~mm}$ was chosen for the cut-off wavelength $\lambda_{\mathrm{c}}$ considering that waviness parameters (Wa and $\mathrm{Wz}$ ) were the most relevant ones for leveling studies. As a result, cut-off values and filters were selected as follows: $100 \mu \mathrm{m}$ for $\lambda_{\mathrm{s}}, 2.5 \mathrm{~mm}$ for $\lambda_{\mathrm{c}}$, and $18 \mathrm{~mm}$ for $\lambda_{\mathrm{f}}$ to obtain Ra, Rz, Wa and $\mathrm{Wz}$ values; and 100 $\mu \mathrm{m}$ low-pass filter and $25 \mathrm{~mm}$ high-pass filter to obtain $\mathrm{Sa}$ values.
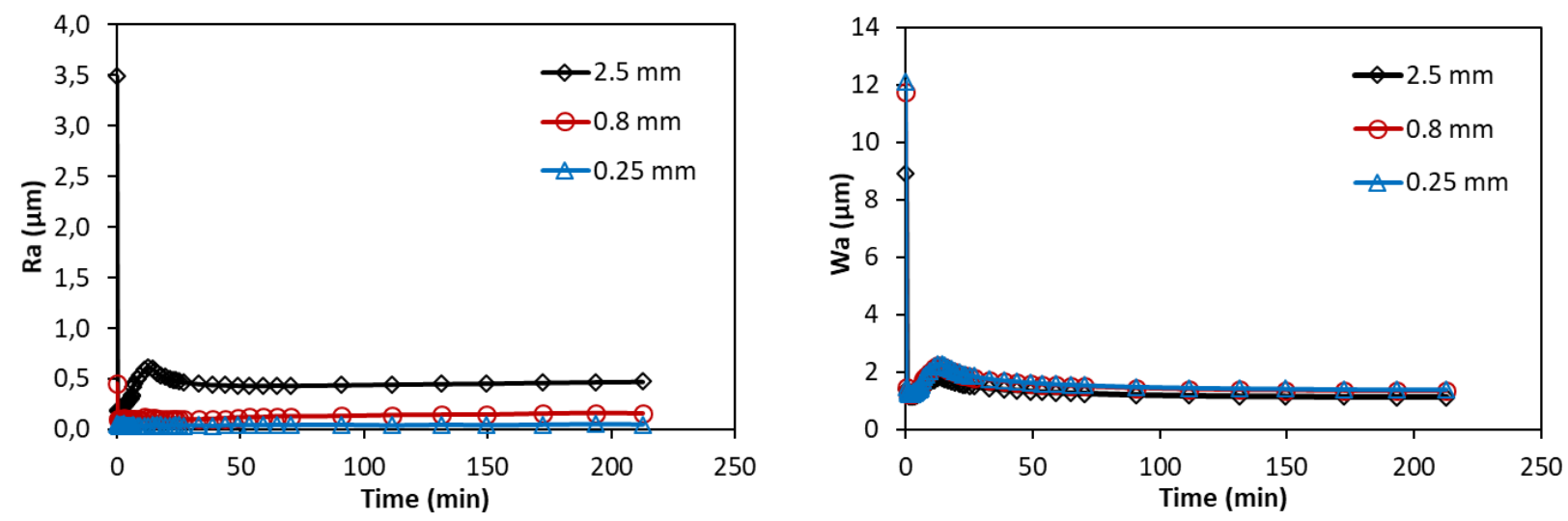

Figure 5. Roughness, Ra (left), and waviness, Wa (right), over time when using different cut-off lengths, $\lambda_{\mathrm{c}}(2.5,0.8$, and $0.25 \mathrm{~mm})$, to the same coating surface measurement [36].

\subsubsection{Evaporation rate experiments}

Evaporation rate experiments were performed for selected samples to obtain solvent evaporation profiles. The coating films were applied under the same conditions as those used in the profilometer. Immediately after coating application and onwards, the coated panels were weighed using a precision balance (ENTRIS623I-1S from Sartorius with an accuracy of $0.001 \mathrm{~g}$ ). In what follows, the ratio $\mathrm{m}_{\mathrm{s}} / \mathrm{m}_{\mathrm{s} 0}$ represents the current residual solvent content to the initial solvent content of the coating (weight basis).

\subsubsection{Spraying application}

To evaluate the effects of ingredients on leveling in more realistic conditions, application using airless spraying equipment was performed by the same person for selected coatings on flat panels (three 
replicates). During spraying, most panels were placed vertically, while some were set in a horizontal position for comparison. In practical use, a layer of tie-coat is normally applied to secure good adhesion of the subsequent top coat. However, it was found that the layer of tie-coat also had surface texture itself. Therefore, a few samples were sprayed without tie-coat to investigate the effects on the top coat of underlying tie-coat. A panel with tie-coat only was also prepared.

Furthermore, surface measurements were conducted using the profilometer after the sprayed samples had dried at room temperature for five days. Each replicate was measured eight times at eight different positions on the panel.

\subsection{Experimental uncertainty analysis}

Considering the entire laboratory procedure, experimental uncertainties are due to the following sources: sample preparation, equipment operation and analysis, and laboratory conditions. The sample uncertainty can be attributed to the inhomogeneity of the coating sample from the same batch, which was kept low by manually stirring the liquid sample prior to experimentation. Operational uncertainties originated from the sample loading position and the sample volume, which could be similar, but not identical in all cases. To minimize the influence of laboratory conditions (e.g., ventilation drafts), experiments were conducted inside a glass cabinet with a stable air circulation at steady ambient temperature.

The uncertainty from the profilometer analysis was estimated by measuring the same surface area 24 times of a dried coating film after spiral application. Standard deviations were within $3 \%$ for roughness ( $\mathrm{Ra}$ and $\mathrm{Rz}$ ) and waviness measurements (Wa and $\mathrm{Wz}$ ) and within $0.4 \%$ for surface roughness (Sa) [36]. 
To estimate the overall experimental uncertainties, which were found to be mainly due to sample inhomogeneity and the loading process, the procedure was repeated three times for the surface measurement and four times for the evaporation rate experiment for coating M2. The results are shown in Figure 6. It can be seen that the experimental uncertainties are fairly low for both surface and solvent evaporation rate measurements.
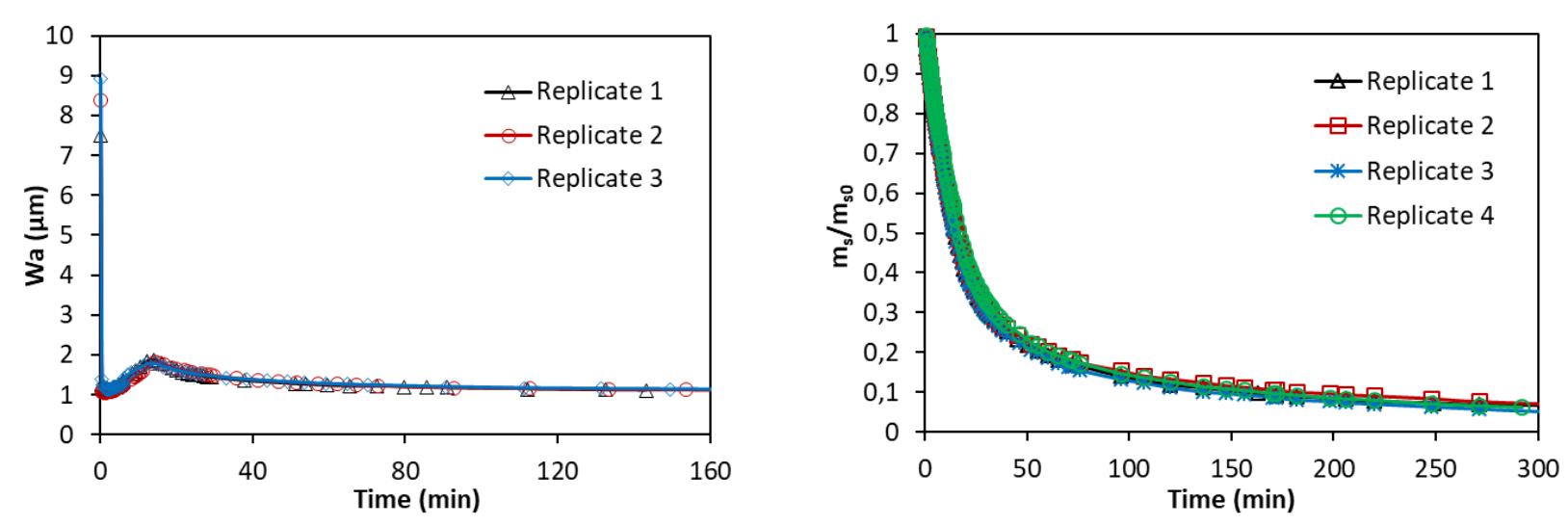

Figure 6. Transient $\mathrm{Wa}$ values for three replicates of surface measurements (left) and the ratio of residual solvent concentration to the initial solvent concentration $\left(\mathrm{m}_{\mathrm{s}} / \mathrm{m}_{\mathrm{s}}\right)$, based on four replicates, over time (right) [36]. Coating M2 was used.

\section{Results and discussion}

In this section, the effects of experimental conditions on leveling are presented together with evaporation rate measurements. Furthermore, the effects of coating ingredients on the leveling of AF coatings are demonstrated and quantified. Finally, results from spraying applications are presented.

\subsection{Effects of applicator type and application conditions}

Experiments using the two types of applicators, shown in Figure 3, were performed under the same conditions for the same coating sample. The results are shown in Figure 7. It can be seen that in the 
spiral applicator case, Wa changes are significantly higher than those of the flat applicator. Meanwhile, the scale of Wa values are much larger than those of the flat applicator. Due to that, the spiral applicator was used in the subsequent experiments to provoke surface waviness and show the leveling process.
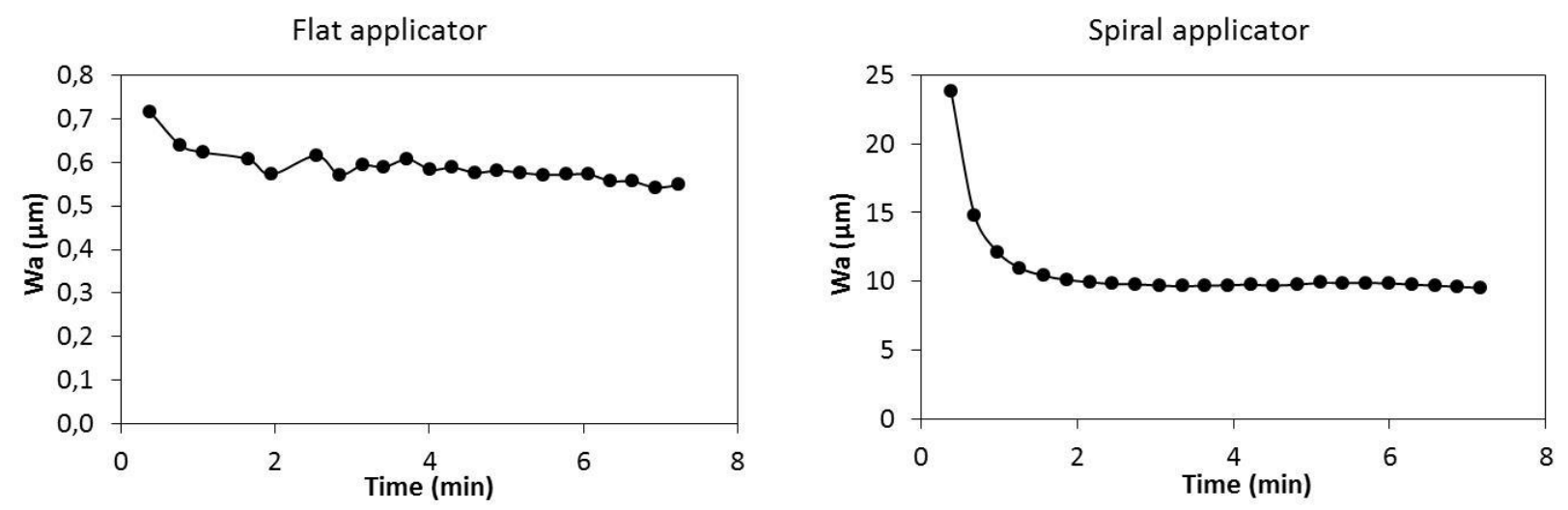

Figure 7. Comparison of the waviness parameter, Wa, over time using two applicators: flat (left) and spiral (right) for a commercial coating. Notice the big difference in scale on the y-axis [36].

Coating application speed and vertical force during application can influence the results. Therefore, experiments using different application speeds $(20,40,60$, and $80 \mathrm{~mm} / \mathrm{s})$ with the same vertical force (270 g) were conducted for coating M2. The effect of application speed (20 to $80 \mathrm{~mm} / \mathrm{s})$ on the $\mathrm{Wa}$ values was measured for the spiral applicator and found to be insignificant [36]. Similar results were found for commercial AF coatings.

Furthermore, the effects of different vertical forces $(0,270,370$, and $540 \mathrm{~g})$ were studied for coating M1-diluted and M2 under the same application speed $(80 \mathrm{~mm} / \mathrm{s})$. The results (not shown) showed that the effects of the vertical force on leveling were insignificant considering the experimental uncertainty [36]. Consequently, the maximum application speed $(80 \mathrm{~mm} / \mathrm{s})$ with constant vertical force $(270 \mathrm{~g})$ was used for the subsequent experiments. 


\subsection{Evaporation rate experiments}

Results of evaporation rate experiments for coatings M1 and M2 are shown in Figure 8, together with changes in the surface texture parameter (Wa).
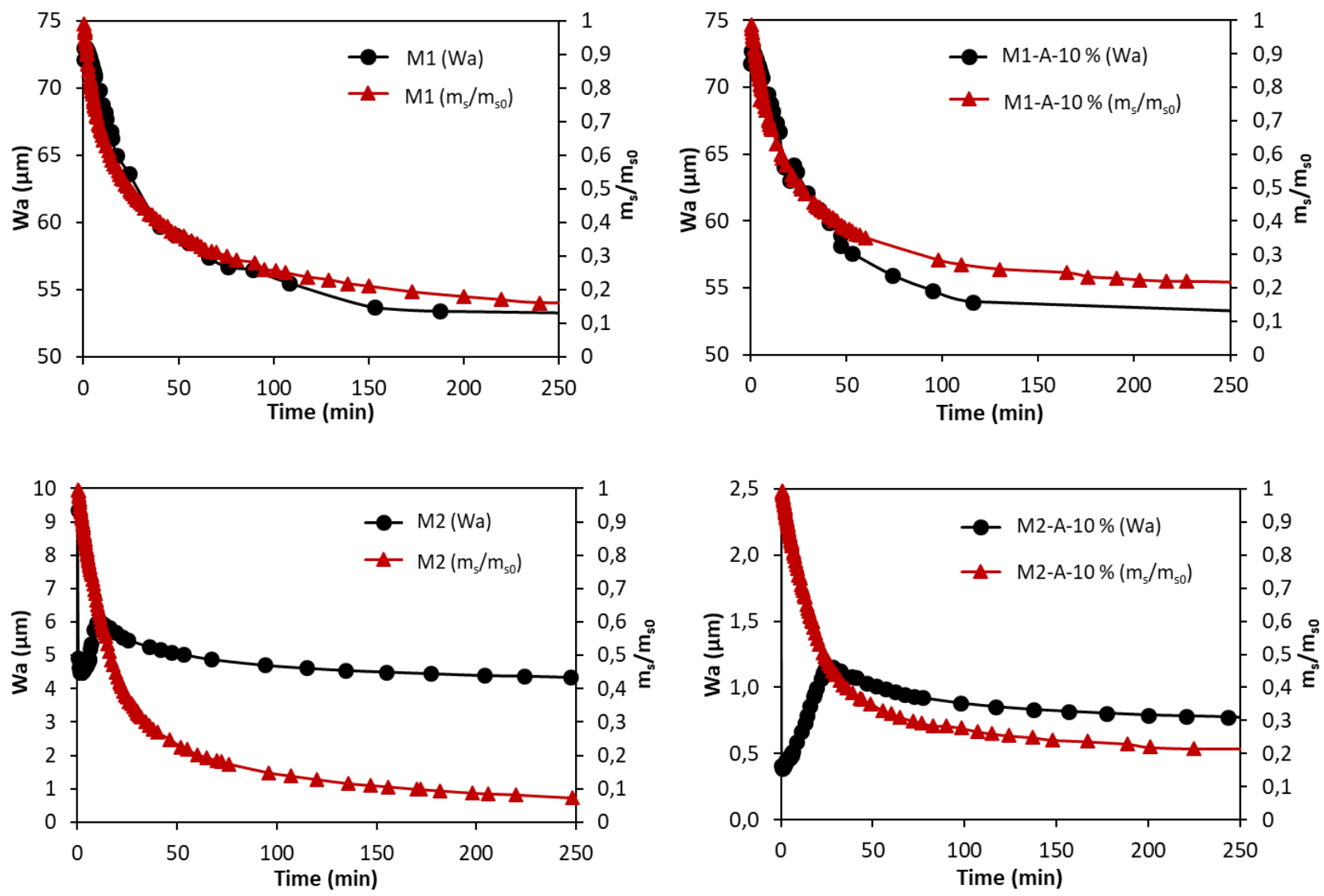

Figure 8. Surface texture parameter (Wa) and the ratio of residual solvent concentration to the initial solvent concentration $(\mathrm{m} s / \mathrm{ms} 0)$ as a function of time. The inserts show: coating M1 (upper left), coating M1 after replacing 10\% of xylene with less volatile solvent (naphtha) A (upper right), coating M2 (bottom left) and coating M2 after replacing 10\% of xylene with less volatile solvent (naphtha) A (bottom right). Notice the large difference in Wa scale between M1 and M2 [36]. 
It can be seen that the solvent evaporation curves initially exhibit a constant evaporation rate period (for both M1 and M2), where the external solvent mass transport resistance dominates. Later the evaporation rate declines and is now dominated (and eventually controlled) by solvent diffusion through the coating film [37].

For the M1 coatings (the two upper curves), the changes in Wa values over time are coupled to the evaporation curves and the associated development in coating viscosity. The replacement of $10 \%$ of xylene with less volatile solvent (naphtha) A has a small effect on the Wa values.

Compared to the M1 coatings, on the other hand, Wa values of the M2 coatings (the two lower curves) seem to develop in a very different way. First of all, in the first part of the constant evaporation rate period, an initial large drop of Wa occurs (the first Wa points are overlapping with the first data points on the evaporation curves). Then Wa increases, before it abruptly starts to decrease. Second, the changes in Wa values are rather small (of the order of one $\mu \mathrm{m}$ ), except the very first data points, compared to those of M1 (about $25 \mu \mathrm{m}$ change). In addition, based on a comparison between left and right hand figures, the replacement of $10 \%$ of xylene with less volatile solvent (naphtha) A, prolongs the initially constant evaporation rate period from about 20 mins to 30 mins and has a correspondingly larger effect on the leveling compared to M1. Furthermore, after the constant evaporation rate period, the evaporation rate declined much faster for $\mathrm{M} 2-\mathrm{A}-10 \%$ than $\mathrm{M} 2$ and a larger amount of solvent A (about 20\%) was trapped in the coating film (the $\mathrm{ms} / \mathrm{ms}$ value did not change much after $250 \mathrm{mins}$ ).

The initial drop in the Wa value that occurs at the very beginning of the evaporation (within one minute) can most likely be attributed to the low viscosity of M2 coatings, which gives the coating more flow ability to level out the peaks and valleys immediately after application. This can be seen from the profiles in Table 3. The images and profile pictures obtained (not shown), verified that, after application, the coating surface, due to the high solvent content, was liquid and glossy, leading to a 
very low surface waviness. After about one minute, due to fast solvent evaporation, the solid content increases to a level, where the liquid surface gradually disappears. During this process, the peaks and valleys become more clear, due to the loss of solvent (see Table $\mathbf{3}$ ), and therefore the Wa value starts to increase. Meanwhile, the pigments inside the coating film are gradually exposed on top of the surface and the surface roughness (not shown) starts to increase. The exposed pigments can be seen in Figure 9.

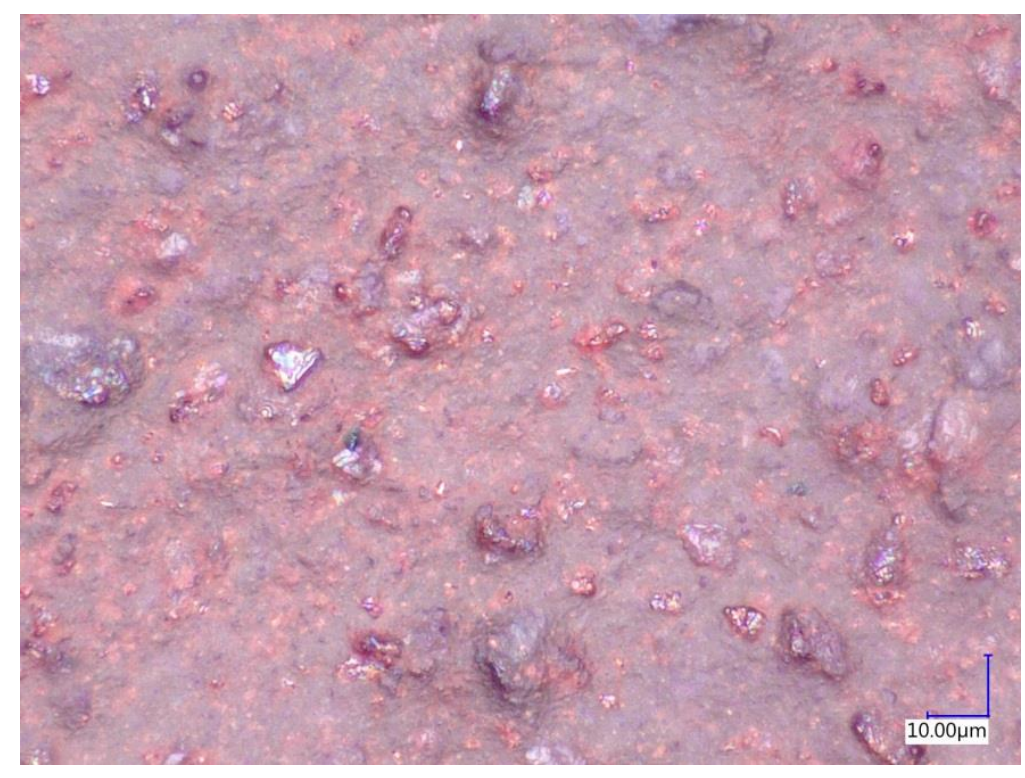

Figure 9. Digital microscope (KEYENCE (VHX-6000)) image of a dried M2 coating surface.

Table 3. Waviness profiles at different times after application for the M2 coating. The same $\mathrm{x}$-axis scale represents the same evaluation location. The same y-axis scale represents the same height range for easy comparison [36]. 


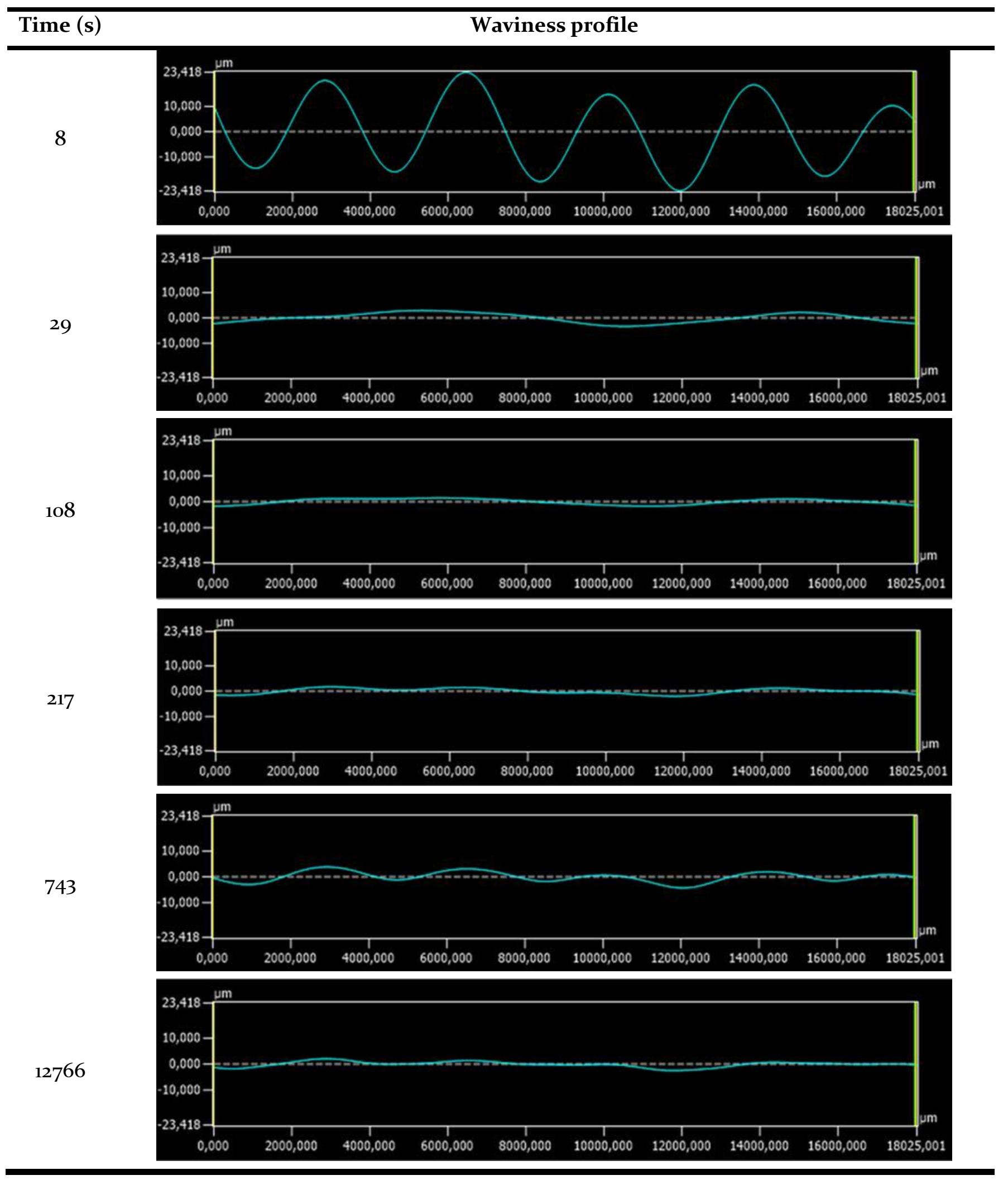


During this process, solvent evaporation is limited mainly by external mass transfer, which corresponds to the constant evaporation rate period. The increase stops after around 10 mins for $\mathrm{M} 2$ and 30 mins for M2-A-10\% from where on the following process is very similar to those of M1 coatings and evaporation continues mainly through intra film solvent diffusion.

Summarizing, there are three leveling stages for low viscosity coatings from this application approach: the initial stage with dramatic drop of surface texture parameters (fast leveling), the middle stage with gradual increase of surface texture parameters, and the final stage with gradual decrease of surface texture parameters (slow leveling). Solvent evaporation is dominated by external mass transport with a high evaporation rate in the first two stages and by internal solvent diffusion in the final stage.

Another evidence for the three leveling stages noticed in the waviness profiles (see Table Fejl! Henvisningskilde ikke fundet.) is that the waviness of the sinusoidal surface ripples decreases significantly from the very first measurement $(8 \mathrm{~s})$ to the second $(29 \mathrm{~s})$. During the three leveling stages, the presence of a Marangoni effect is not expected because no clear reversal process was observed for the samples, as seen from the profiles in Table 3. Consequently, we speculate that the most probable reason is the viscosity increase that is coupled mainly to the solvent evaporation. Note that for the transient waviness recordings, it is not possible to separate the influence of solvent evaporation and thixotropy on the viscosity. However, we expect the solvent evaporation to be the dominating effect because of the transition from liquid coating to a viscoelastic solid. Afterwards, the waviness height of peaks and valleys enhance for a period (108-743 s) due to the solvent evaporation and subsequently starts to decrease (after $743 \mathrm{~s}$ ). 


\subsection{Effects of coating ingredients on leveling of coatings M1 and M2}

The effects of replacing xylene with less volatile solvent (naphtha) A with different concentrations on leveling of coating M1 are shown in Figure 10. It can be seen that the effects are insignificant considering the experimental uncertainty. The effects of adding $2 \%$ of polyether-modified polymethylalkylsiloxane solution (silicone surfactant/leveling additive) B, salt of a polymer with acidic groups (wetting and dispersing agent) $\mathrm{C}$, and poly(dimethyl)siloxane (silicone additive) D on leveling of coating M1 were also found to be insignificant (plots not shown).

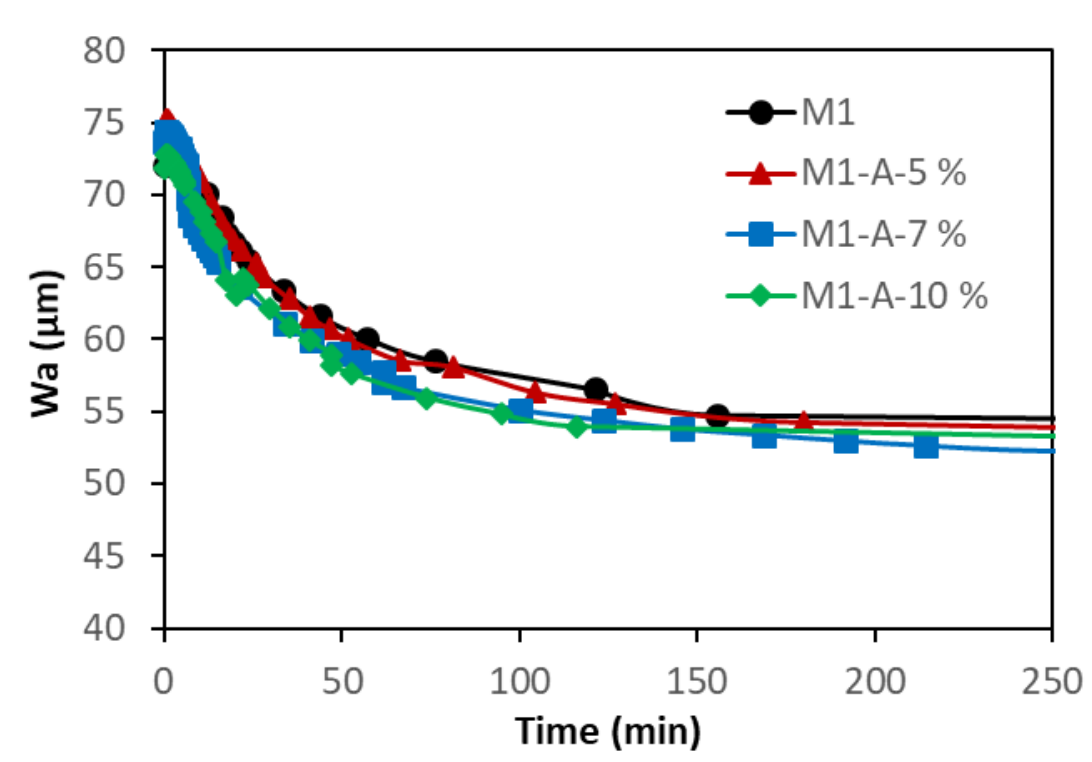

Figure 10. Surface texture parameter (Wa) over time when replacing different percentages $(0,5,7$, and $10 \%$ ) of xylene solvent with a less volatile solvent (naphtha) A for coating M1 [36].

The insignificant effects might be attributed to the high viscosity of the coating M1 which results in a low flow ability. After application, the top coating surface in contact with air rapidly formed a 'skin'. However, due to solvent remaining inside the coating film, leveling could still take place, and the rate of solvent evaporation was limited by internal solvent diffusion rather than external mass transport. 
Due to the high viscosity of coating M1, a similar formulation M2 with a lower viscosity (within the viscosity range of commercial AF coatings) was formulated. Figure $\mathbf{1 1}$ shows the effects of different additives and the less volatile solvent on leveling of coating M2. Specifically, the Wa values of different coatings at different times are listed in Table 4.
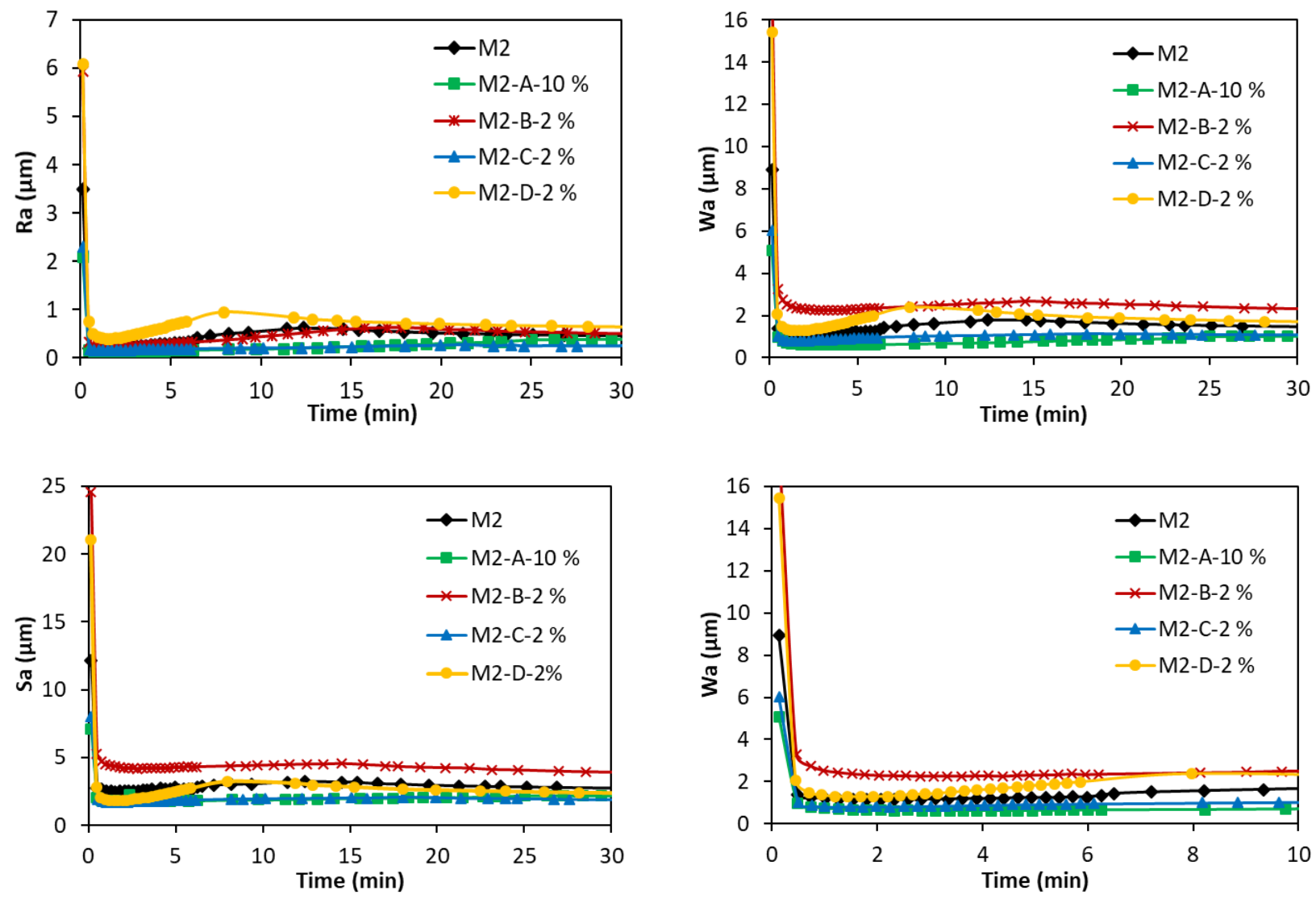

Figure 11. Surface texture parameters ( $\mathrm{Ra}, \mathrm{Wa}$ and $\mathrm{Sa}$ ) over time after adding $2 \%$ of polyethermodified polymethylalkylsiloxane solution (silicone surfactant/leveling additive) B, salt of a polymer with acidic groups (wetting and dispersing agent) C, poly(dimethyl)siloxane (silicone additive) D, and after replacing $10 \%$ of xylene with less volatile solvent (naphtha) A for coating M2. The lower right hand plot shows Wa changes within the first 10 mins [36]. 
Table 4. The Wa values of the different coatings at different leveling times. For uncertainty levels, see the analysis provided in section 2.5 .

\begin{tabular}{cccccc}
\hline \multirow{2}{*}{ Time $(\min )$} & \multicolumn{5}{c}{ Wa $(\mu \mathrm{m})$} \\
\cline { 2 - 6 } & M2 & M2-A-10\% & M2-B-2\% & M2-C-2\% & M2-D-2\% \\
\hline 0.13 & 8.92 & 5.08 & 18.04 & 6.01 & 15.43 \\
1.27 & 1.15 & 0.68 & 2.44 & 0.81 & 1.30 \\
2.32 & 1.14 & 0.61 & 2.28 & 0.80 & 1.30 \\
3.88 & 1.18 & 0.61 & 2.27 & 0.87 & 1.59 \\
4.40 & 1.20 & 0.61 & 2.25 & 0.89 & 1.68 \\
17.92 & 1.73 & 0.84 & 2.58 & 1.13 & 1.91 \\
26.85 & 1.62 & 1.02 & 2.36 & 1.08 & 1.74 \\
\hline
\end{tabular}

It is evident from the plots that the addition of $2 \%$ of silicone surfactant B increases slightly the waviness, Wa, and the entire surface roughness, Sa, which indicates that silicone surfactant B has negative effects on leveling performance of coating M2. After adding $2 \%$ of poly(dimethyl)siloxane (silicone additive) $\mathrm{D}$, the roughness, $\mathrm{Ra}$, and waviness, Wa, values are increased though the entire surface roughness is not much affected. Therefore, poly(dimethyl)siloxane (silicone additive) does not have positive effects on leveling of coating M2. All the plots show that adding $2 \%$ of wetting and dispersing agent $\mathrm{C}$ and replacing $10 \%$ of xylene with a less volatile solvent (naphtha) A decrease slightly all the surface texture parameters. However, the reductions are not great. These effects are further investigated in a later section using spraying application.

\subsection{Effects of viscosity on leveling and evaporation}

The major difference between M1 and M2 coatings is the viscosity which leads to the different leveling behaviors after spiral application. Therefore, to further investigate the effects of viscosity on leveling, a 
comparison of model formulations with three viscosities $(8,4.3,2.2 \mathrm{~Pa} \cdot \mathrm{s}$ ) is shown in Figure 12 (other surface texture parameters show similar results which are not shown).

The effects of viscosity on leveling behavior and surface texture of the final dry coatings are significant. First, it can be seen that different viscosities give different initial values of Wa at about 15 second. Second, there is an initial drop after application for coating M1-diluted, which is similar to coating M2. However, after the initial drop, the increasing value of Wa did not occur in a similar way to coating M2. The possible reason may be due to the higher viscosity of coating M1-diluted compared to coating M2. The higher viscosity probably limits the initial drop to a much lower extent (due to the low flow ability) so that the increasing process of Wa (arising from the enhanced peaks and valleys) was not remarkable. Notice that the second data point of M1-diluted dropped to about $55 \mu \mathrm{m}$ which is far higher than that of M2 (about $5 \mu \mathrm{m}$ ). On the other hand, it can be seen that a lower viscosity leads to a faster leveling rate and a lower final waviness (a better leveling), which is consistent with the Orchard theory [13].

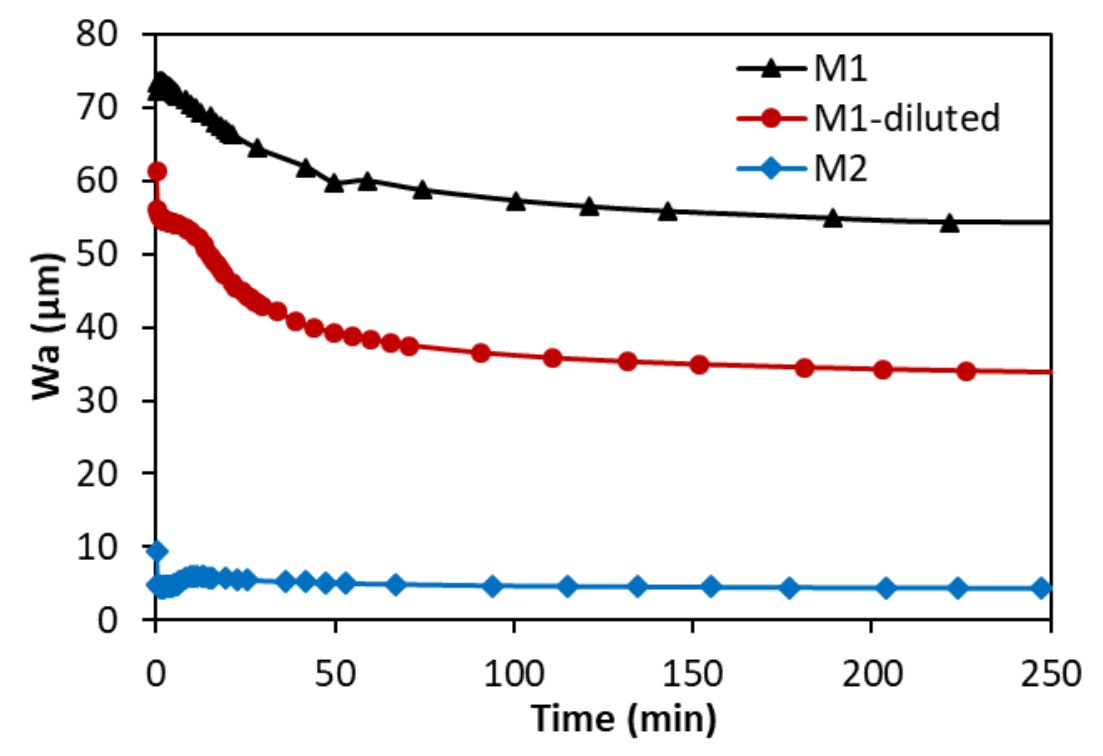


Figure 12. Surface texture parameter (Wa) as a function of time for model formulations with different viscosities measured at a shear rate of $117.4 \mathrm{~s}^{-1}: \mathrm{M} 1(8 \mathrm{~Pa} \cdot \mathrm{s}), \mathrm{M} 1$-diluted (4.3 Pa.s), and M2 (2.2 Pa.s) [36].

\subsection{Spraying application and sagging control}

To further evaluate the ingredient effects on leveling of M2 coating, samples M2, M2-C-2\%, and M2A-10\% were sprayed vertically and horizontally on flat panels for surface measurements. However, sagging appeared on the vertically sprayed panels, especially for the sample M2-C-2\%. Furthermore, to evaluate the effects of the underlying tie-coat layer, a pure tie-coat layer sprayed on a flat panel was also measured. The average values from all measurements are summarized in Table $\mathbf{5}$.

Table 5. Comparison of surface measurements from different application methods. Each value is the average of three replicates. Only the highest standard deviation is indicated for each parameter [36].

\begin{tabular}{|c|c|c|c|c|c|c|}
\hline $\begin{array}{l}\text { Application } \\
\text { method }\end{array}$ & Sample & $\begin{array}{c}\mathrm{Ra}(\mu \mathrm{m}) \\
\pm 0.12\end{array}$ & $\begin{array}{c}\mathrm{Rz}(\boldsymbol{\mu m}) \\
\pm 0.78\end{array}$ & $\begin{array}{c}\text { Wa }(\boldsymbol{\mu m}) \\
\pm 0.44\end{array}$ & $\begin{array}{c}\mathrm{Wz}(\mu \mathrm{m}) \\
\pm \mathbf{1 . 8 6}\end{array}$ & $\begin{array}{c}\text { Sa }(\boldsymbol{\mu m}) \\
\pm 0.35\end{array}$ \\
\hline \multirow{3}{*}{$\begin{array}{l}\text { Drawdown } \\
\text { (no sagging) }\end{array}$} & M2 & 0.47 & 2.10 & 1.13 & 6.41 & 2.26 \\
\hline & M2-A-10\% & 0.34 & 1.68 & 0.70 & 3.64 & 1.61 \\
\hline & M2-C-2\% & 0.44 & 2.28 & 0.88 & 5.35 & 1.58 \\
\hline \multirow{3}{*}{$\begin{array}{c}\text { Spraying } \\
\text { horizontally } \\
\text { (no sagging) }\end{array}$} & M2 & 0.96 & 5.52 & 1.89 & 9.26 & 3.38 \\
\hline & M2-A-10\% & 0.96 & 5.08 & 1.84 & 9.62 & 3.57 \\
\hline & M2-C-2\% & 0.90 & 4.67 & 1.61 & 8.32 & 2.94 \\
\hline Spraying & M2 & 1.16 & 5.83 & 3.36 & 16.40 & 5.55 \\
\hline
\end{tabular}




\begin{tabular}{|c|c|c|c|c|c|c|}
\hline vertically & M2-C-2\% & 1.27 & 5.84 & 3.58 & 17.64 & 5.59 \\
\cline { 2 - 6 } (sagging) & Tie-coat & 2.77 & 13.28 & 4.53 & 24.21 & 7.12 \\
\hline
\end{tabular}

Comparing the results from drawdown and horizontally spraying application without sagging, it can be seen that the values of all the parameters from spraying application are higher than those from drawdown application for the same sample. The effects of adding $2 \%$ of $\mathrm{C}$ and replacing $10 \%$ of xylene with A on leveling are insignificant when employing spraying application. In addition, the values of those parameters for pure tie-coat are much higher than those with one layer of top coat after vertical spraying, which means that the top coat can cover some of the tie-coat surface texture.

Due to sagging, the parameter values from vertical spraying are higher than those from horizontal spraying, in particular for waviness. Therefore, during spraying application on ship hulls, a better leveling effect can easily be compromised by unacceptable sagging values.

\subsubsection{Effects of tie-coat and anti-sagging agent $E$}

Coating M3 with anti-sagging agent E was vertically sprayed on flat panels with and without tie-coat (the same as used for coating M2). No sagging was observed. The results of surface measurements are shown in Figure 13.

It can be seen that all surface parameters are increased after spraying with underlying tie-coat. It confirms again the negative effect of the tie-coat on the surface texture of the final top coat. Compared to the results of coating M2 sprayed vertically with sagging (see Table 5), surface texture parameters of coating M3 are increased after adding anti-sagging agent. It indicates that although anti-sagging agents can stop sagging, they limit leveling as well. 


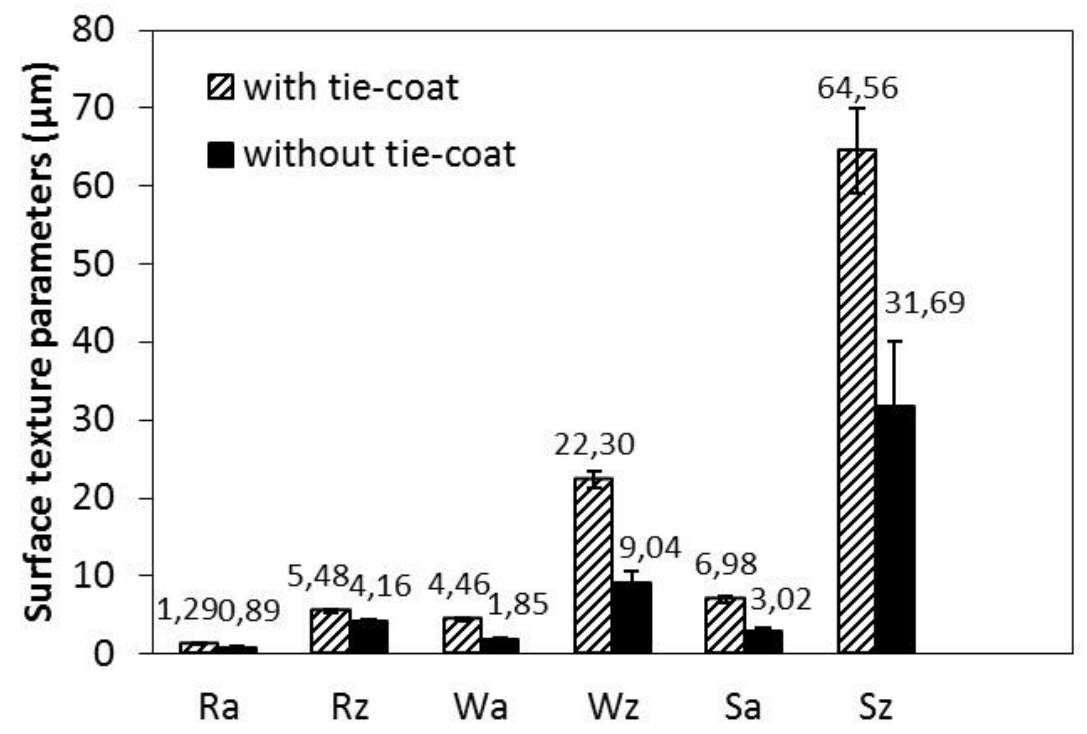

Figure 13. Surface texture parameters of dried model formulation (M3) with anti-sagging agent E after vertical spraying on flat panels with and without tie-coat. Each data point is the average of all measurements and the error bars shown represent the standard deviations of all measurements [36].

\subsubsection{Effects of coating ingredients on leveling of coating $M 3$}

The effects of wetting and dispersing agent $\mathrm{C}$ and less volatile solvent (naphtha) A on leveling of coating M3 were further investigated. Samples M3, M3-A-10\%, and M3-C-2\% were sprayed vertically on flat panels with tie-coat. No sagging was visually observed when the wet film thickness was controlled below $300 \mu \mathrm{m}$ for M3, $350 \mu \mathrm{m}$ for M3-A-10\%, and $275 \mu \mathrm{m}$ for M3-C-2\%. Furthermore, the three samples were also measured after spiral-drawdown application using the profilometer. The surface measurement results of the three samples are summarized and compared with M2 samples in Figure 14 after spiral-drawdown applications and in Figure $\mathbf{1 5}$ after vertical spraying applications. 

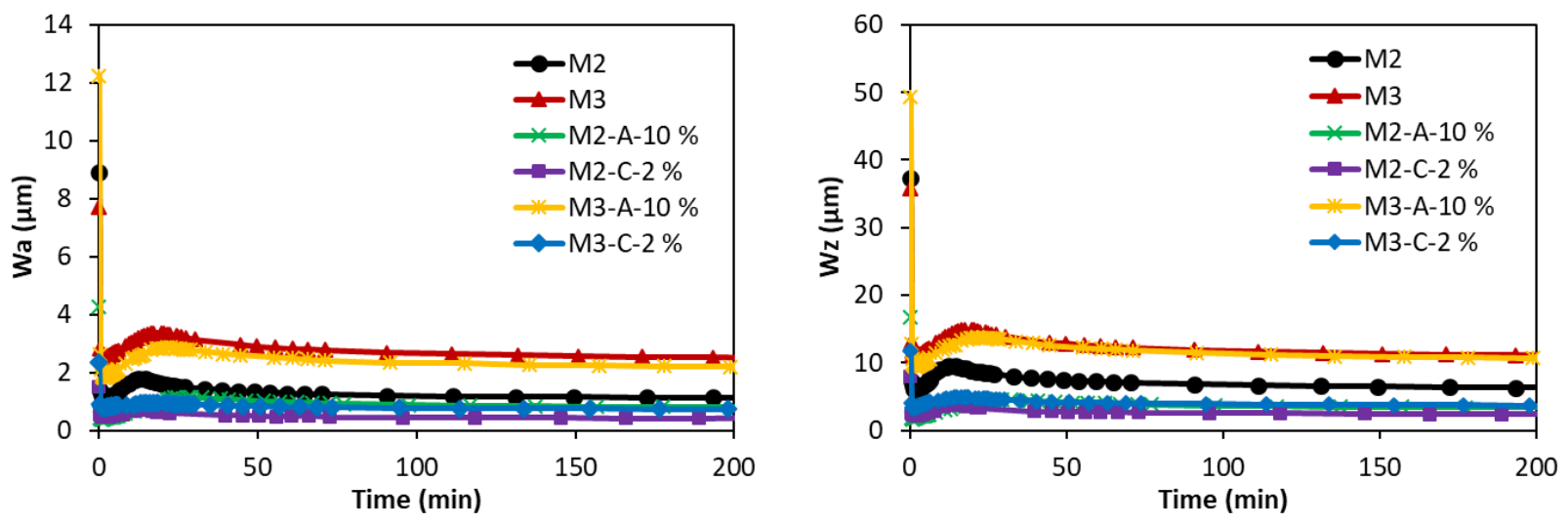

Figure 14. Waviness parameters, Wa and Wz, over time for coating M2 (without anti-sagging agent E), M3 (with anti-sagging agent E), M2-A-10\% (without anti-sagging agent E and replacing 10\% of xylene with less volatile solvent, naphtha, A), M2-C-2\% (without anti-sagging agent E and with dispersing agent $\mathrm{C}$ ), M3-A-10\% (with anti-sagging agent $\mathrm{E}$ and replacing $10 \%$ of xylene with less volatile solvent, naphtha, A), and M3-C-2\% (with anti-sagging agent E and dispersing agent C) [36].

Figure 14 shows that after using anti-sagging agent E, surface waviness of coating M3 increases compared to coating M2, which means that leveling becomes worse when adding anti-sagging agent. This is in agreement with the aforementioned results from the spraying application. For coating M3, replacing $10 \%$ of xylene with less volatile solvent (naphtha) A does not show significant effects in decreasing surface waviness. Nevertheless, adding $2 \%$ of dispersing agent $\mathrm{C}$ decreases the waviness of M3 largely to a similar effect level as M2-A-10\%. It means that it is possible to obtain good leveling performance with anti-sagging agent involved in the formulation.

The surface measurement results of the final dried coating after spraying are different as shown in Figure 15. Adding $2 \%$ of dispersing agent $\mathrm{C}$ and replacing $10 \%$ of xylene with less volatile solvent (naphtha) A increase surface waviness of coating M3, which indicates that surface leveling of coating 
M3 becomes worse. The possible reason may be due to the uncertainty from spraying application (e.g., human operation uncertainties). Another reason may be that the spray ability of those samples was not tuned from the formulation point of view. Therefore, the effects of ingredients on leveling of model formulations, using the spiral-drawdown application, could not be reproduced with spraying application.

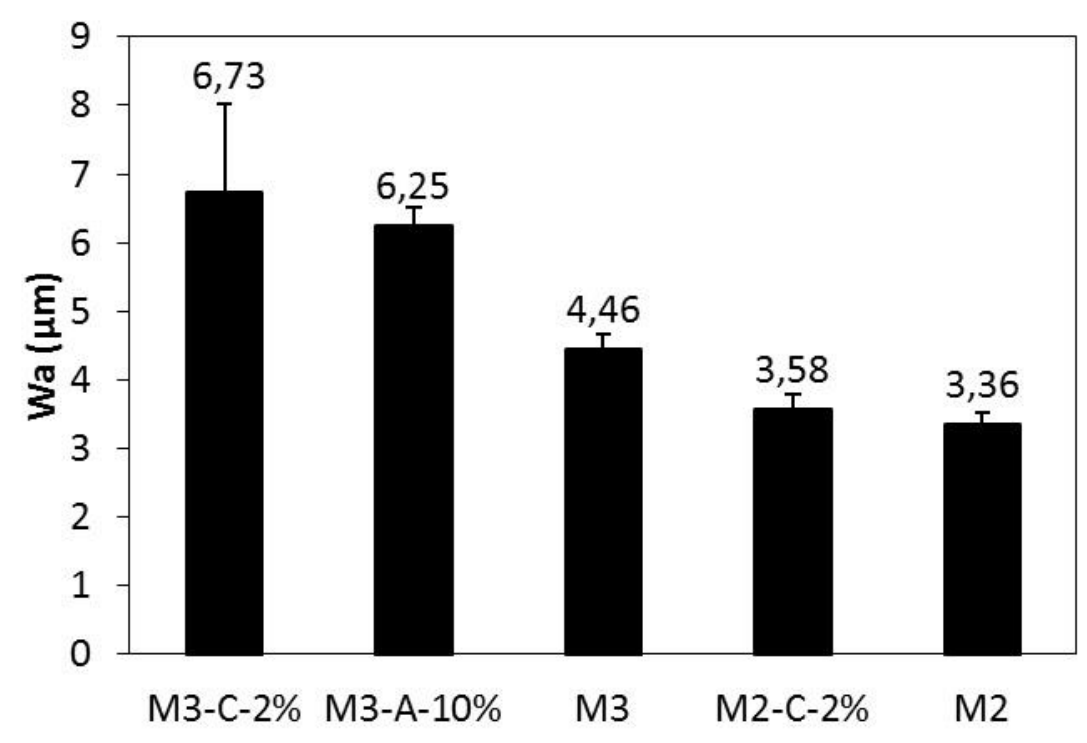

Figure 15. Wa values of dried samples M3-C-2\% (with anti-sagging agent $\mathrm{E}$ and dispersing agent $\mathrm{C}$ ), M3-A-10\% (with anti-sagging agent E and replacing 10\% of xylene with less volatile solvent, naphtha, A), M3 (with anti-sagging agent E), M2-C-2\% (without anti-sagging agent E and with dispersing agent C), M2 (without anti-sagging agent E) after spraying vertically with tie-coat. Each data point is the average of all measurements and the error bars shown represent standard deviations based on all measurements [36]. 


\section{Conclusions}

An approach for quantitatively measuring leveling performance of coatings was developed using a combination of an optical 3D profilometer and a retrofitted automatic film application system. Using this approach on model formulations for AF coatings, the effects of coating ingredients on leveling performance and the underlying leveling mechanisms were investigated. A special made spiral applicator was found to generate well-defined sinusoidal surface textures with waviness pattern.

It was found that leveling rate was strongly coupled to the solvent evaporation rate and the associated development in coating viscosity. The leveling behavior for coatings with a low viscosity developed quite differently compared to coatings with a high viscosity. Three leveling stages, coupled to the evaporation process, were discovered for less viscous coatings, while high viscous coatings only went through the final stage.

Due to a less controlled process, the effects of additives and solvents on leveling of model formulations observed from the spiral-drawdown application were not found when using spraying application. Moreover, when coatings are sprayed on ship hulls, a better leveling effect can be easily compromised by sagging problems.

\section{Acknowledgments}

The authors would like to thank Johan Scholl and Ciaran Dunbar for their help with laboratory work. Funding: This work was conducted under the partnership of Blue INNOship. Financial support from the Hempel Foundation to CoaST (The Hempel Foundation Coatings Science and Technology Centre) and from Innovation Fund Denmark, the Danish Maritime Fund, A.P. Møller - Mærsk A/S and Hempel A/S to the work is gratefully acknowledged. 


\section{Data availability}

The raw data required to reproduce these findings are available to download from [https://data.mendeley.com/datasets/crchhr9xt7/draft?a=70981e12-a98d-47aa-8f61-c290aaa5c74d].

The processed data required to reproduce these findings are available to download from [https://data.mendeley.com/datasets/crchhr9xt7/draft?a=70981e12-a98d-47aa-8f61-c290aaa5c74d].

\section{References}

[1] M.P. Schultz, Effects of coating roughness and biofouling on ship resistance and powering, Biofouling. 23 (2007) 331-341. doi:10.1080/08927010701461974.

[2] X. Wang, S.M. Olsen, E. Andres Martinez, K.N. Olsen, S. Kiil, Drag resistance of ship hulls: effects of surface roughness of newly applied fouling control coatings, coating water absorption, and welding seams, J. Coatings Technol. Res. 15 (2018) 657-669. doi:10.1007/s11998-0180054-7.

[3] C.T. Patton, Paint Flow and Pigment Dispersion, second, Wiley-Interscience, New York, 1979.

[4] M. Lejars, A. Margaillan, C. Bressy, Fouling release coatings: A nontoxic alternative to biocidal antifouling coatings, Chem. Rev. 112 (2012) 4347-4390. doi:10.1021/cr200350v.

[5] F. Myan, J. Walker, O. Paramor, The interaction of marine fouling organisms with topography of varied scale and geometry: A review, Biointerphases 8 (2013) 1-13. doi: 10.1186/1559-4106$8-30$

[6] R.L. Townsin, D. Byrne, T.E. Svensen, A. Milne, Estimating the Technical and Economic Penalties of Hull and Propeller Roughness, SNAME Transactions 89 (1981) 295-318.

[7] International Organization for Standardization, Geometrical product specifications (GPS)Surface texture: Profile method-Nominal characteristics of contact (stylus) instruments. (ISO 
3274), 1996.

[8] International Organization for Standardization, Geometrical Product Specifications (GPS)Surface texture: Profile method-Rules and procedures for the assessment of surface texture. (ISO 4288), 1996.

[9] T.G. Mezger, The Rheology Handbook, Third revi, Vincentz Network, Hanover, 2011.

[10] A. Quach, Polymer coatings. Physics and Mechanics of leveling, Ind.Eng.Chem.Prod.Res.Develop. 12 (1973) 110-116. doi:10.1021/i360046a003.

[11] R.K. Waring, An Analytical Study of Leveling, J. Rheol. (N. Y. N. Y). 2 (1931) 307-314. doi:10.1122/1.2116383.

[12] N.D.P. Smith, S.E. Orchard, A.J. Rhind-Tutt, The Physics of Brushmarks, Surf. Coatings Int. 44 (1961) 618-633. doi:jglobal.jst.go.jp/en/public/201602000696958456.

[13] S.E. Orchard, On surface leveling in viscous liquids and gels, Appl. Sci. Res. Sect. A. 11 (1963) 451-464. doi:https://doi.org/10.1007/BF03184629.

[14] W.S. Overdiep, The leveling of paints, Prog. Org. Coatings. 14 (1986) 159-175. doi:https://doi.org/10.1016/0033-0655(86)80010-3.

[15] G.M. Kontogeorgis, S. Kiil, Introduction to applied colloid and surface chemistry, Chapter 13: Foams, John Wiley \& Sons, Ltd., United Kingdom, 2016, doi: 10.1002/9781118881194

[16] S.K. Wilson, The derivation and analysis of a model of the drying process of a paint film, Surf. Coatings Int. Part B Coatings Trans. 80 (1997) 162-167. doi:10.1007/BF02692636.

[17] S.K. Wilson, The levelling of paint films, IMA J. Appl. Math. 50 (1993) 149-166. doi:10.1093/imamat/50.2.149.

[18] S.D. Howison, J.A. Moriarty, J.R. Ockendon, E.L. Terrill, S.K. Wilson, A mathematical model for drying paint layers, J. Eng. Math. 32 (1997) 377-394. doi:10.1023/A:1004224014291. 
[19] M.H. Eres, D.E. Weidner, L.W. Schwartz, Three-Dimensional Direct Numerical Simulation of Surface-Tension-Gradient Effects on the Leveling of an Evaporating Multicomponent Fluid, Langmuir. 15 (1999) 1859-1871. doi:10.1021/la980414u.

[20] S. Livescu, R.V. Roy, L.W. Schwartz, Leveling of thixotropic liquids, J. Nonnewton. Fluid Mech. 166 (2011) 395-403. doi:10.1016/j.jnnfm.2011.01.010.

[21] O. Cohu, A. Magnin, The levelling of thixotropic coatings, Prog. Org. Coatings. 28 (1996) 8996. doi:https://doi.org/10.1016/0300-9440(95)00556-0.

[22] S. Kojima, T. Moriga, K. Takenouchi, The leveling of thermosetting waterborne coatings. Part III: Leveling under controlled conditions, Polym. Eng. Sci. 35 (1995) 1949-1954. doi:10.1002/pen.760332004.

[23] S. Kojima, T. Moriga, K. Takenouchi, The leveling of thermosetting Waterborne Coatings. Part IV: Effects of film thickness, Polym. Eng. Sci. 35 (1995) 1955-1961. doi:https://doi.org/10.1002/pen.760352407.

[24] S.J. Dodge, Quantitative Measures of Leveling, J. Paint Technol. 44 (1972) 72-78.

[25] S. Mahmoodi, H. Guoqing, M.N. Khajavi, Two-dimensional spin coating with a vertical centrifugal force and the effect of artificial gravity on surface leveling, J. Coatings Technol. Res. 13 (2016) 1123-1137. doi:10.1007/s11998-016-9823-3.

[26] M. Bosma, R. Brinkhuis, E. Rensen, R. Watson, A new method for the quantitative determination and prediction of sag and levelling in powder coatings, Prog. Org. Coatings. 72 (2011) 26-33. doi:10.1016/j.porgcoat.2011.01.010.

[27] C.A. Peters, M.E. Nichols, K.R.J. Ellwood, The evolution of surface texture in automotive coatings, J. Coatings Technol. Res. 8 (2011) 469-480. doi:10.1007/s11998-011-9333-2.

[28] F. Seeler, C. Hager, O. Tiedje, M. Schneider, Simulations and experimental investigation of 
paint film leveling, J. Coatings Technol. Res. 14 (2017) 767-781. doi:10.1007/s11998-0179934-5.

[29] L.W. Schwartz, D.E. Weidner, R.R. Eley, An Analysis of the Effect of Surfactant on the Leveling Behavior of a Thin Liquid Coating Layer, Langmuir. 11 (1995) 3690-3693. doi:10.1021/la00010a017.

[30] M.J. King, The measurement of ship hull roughness, Wear. 83 (1982) 385-397. doi:10.1016/0043-1648(82)90191-0.

[31] E.S. Gadelmawla, M.M. Koura, T.M.A. Maksoud, I.M. Elewa, H.H. Soliman, Roughness parameters, J. Mater. Process. Technol. 123 (2002) 133-145. doi:10.1016/S09240136(02)00060-2.

[32] A. Boryczko, Distribution of roughness and waviness components of turned surface profiles, Metrol. Meas. Syst. 17 (2010) 611-620. doi:10.2478/v10178-010-0050-4.

[33] E. Martinelli, M.K. Sarvothaman, G. Galli, M.E. Pettitt, M.E. Callow, J.A. Callow, S.L. Conlan, A.S. Clare, A.B. Sugiharto, C. Davies, D. Williams, Poly(dimethyl siloxane) (PDMS) network blends of amphiphilic acrylic copolymers with poly(ethylene glycol)-fluoroalkyl side chains for fouling-release coatings. II. Laboratory assays and field immersion trials, Biofouling. 28 (2012) 571-582. doi:10.1080/08927014.2012.697897.

[34] International Organization for Standardization, Geometrical product specifications (GPS)Surface texture: Areal-Part 2: Terms, definitions and surface texture parameters. (ISO 25178-2), 2012.

[35] International Organization for Standardization, Geometrical Product Specifications (GPS)Surface texture: Profile method-Terms, definitions and surface texture parameters. (ISO 4287), 1998. 
[36] [dataset] X. Wang, C.E. Weinell, V. Tobar, S.M. Olsen, S. Kiil, Data for: Leveling measurements of antifouling coatings using an optical profilometer: effects of additives and solvent concentration and type, Mendeley Data, Draft (of version 1), 2018, doi:10.17632/crchhr9xt7.1

[37] S. Kiil, Quantification of simultaneous solvent evaporation and chemical curing in thermoset coatings, J. Coatings Technol. Res. 7 (2010) 569-586. doi:10.1007/s11998-010-9246-5. 